\title{
O DESAFIO DA DELIMITAÇÃo DE ÁREAS DE PRESERVAÇÃo PERMANENTE ${ }^{1}$
}

\author{
Carlos Antonio Alvares Soares Ribeiro² , Vicente Paulo Soares ${ }^{2}$, Angelo Marcos Santos Oliveira ${ }^{3}$ e José \\ Marinaldo Gleriani ${ }^{2}$
}

\begin{abstract}
RESUMO - A demarcação das áreas de proteção no topo de morros e ao longo dos divisores d'água é um processo complexo, dificultando a fiscalização e, por conseguinte, o fiel cumprimento da legislação. Como alternativa aos métodos tradicionalmente utilizados - mapas topográficos, levantamentos de campo e uso dos restituidores - na execução dessa tarefa, apresenta-se uma nova metodologia, alicerçada na modelagem numérica do relevo e implementada em um sistema de informações geográficas. O processo é todo automatizado e alicerça-se em um conceito relativamente novo de modelos digitais de elevação hidrologicamente consistentes, tendo como vantagens a confiabilidade e a reprodutibilidade dos resultados obtidos, além da economia óbvia de tempo e mão-de-obra. A partir da disponibilização gratuita pela NASA dos dados SRTM (Shuttle Radar Topography Mission) para todo o continente americano, os resultados indicaram claramente que a aplicação da Lei Florestal no Brasil passa a ser tão-somente uma vontade política.
\end{abstract}

Palavras-chave: Áreas de preservação permanente, legislação ambiental e manejo de bacias hidrográficas.

\section{THE CHALLENGE OF THE DELINEATION OF NATURAL PRESERVES}

\begin{abstract}
The demarcation of permanent preservation areas is a complex process, jeopardizing both the surveillance tasks and law enforcement. This paper presents a GIS-based alternative to the traditional laborintensive approach - manual features extraction using paper maps and photogrammetry techniques. The methodology relies on the new recent concept of hydrologically correct digital elevation models and has as principal advantages the consistency and reproducibility of the results, besides savings on both time and labor. Considering the recent availability by NASA of SRTM (Shuttle Radar Topography Mission) data on a continental scale, the results clearly show that, from now on, the enforcement of the Forest Code in Brazil is just a matter of political willingness.
\end{abstract}

Key words: Permanent preservation areas, environmental legislation, watershed management.

\section{INTRODUÇÃO}

Nas últimas duas décadas tem aumentado sensivelmente a preocupação mundial com o crescimento alarmante da taxa de desmatamento das florestas tropicais e com o seu impacto na biodiversidade do Planeta. Embora ocupem apenas $7 \%$ da área total, as florestas tropicais abrigam metade da biodiversidade da Terra
(RAVIKANTH et al., 2000). Entre 1990 e 2000, a taxa média anual de desmatamento mundial dessas florestas foi estimada em 15,2 x $10^{6}$ ha. Na América do Sul, desmataram-se, em média, 3,72 x $10^{6}$ ha/ano, enquanto nesse mesmo período o Brasil viu perder $23 \times 10^{6}$ ha de suas florestas (FAO, 2001).

A conversão de áreas para as atividades

\footnotetext{
${ }^{1}$ Recebido em 20.04.2004 e aceito para publicação em 25.11.2004.

${ }^{2}$ Departamento de Engenharia Florestal - Universidade Federal de Viçosa - 35670-000 Viçosa - MG.

${ }^{3}$ Programa de Pós-Graduação em Ciência Florestal da UFV.
} 
agropecuárias é apontada como a principal causa de desmatamento em todo o mundo (HOUGHTON, 1994). Historicamente, o processo de colonização e consolidação do território brasileiro tem-se pautado na exploração predatória de seus recursos naturais, afetando negativamente a qualidade e a disponibilidade dos recursos hídricos, principalmente os superficiais. Vastas extensões de matas exuberantes foram simplesmente suprimidas ao longo dos séculos para dar espaço à agricultura, pecuária e mineração. O declínio da produtividade agrícola, aliado a uma visão miópica da abundância dos recursos naturais, força, continuamente, a conversão de mais e mais terras para a agricultura, deixando um rastro de áreas degradadas. Fica a cargo tão-somente da natureza a tarefa de recuperarse da agressão sofrida. Embora haja consenso, em nível mundial, de que não se pode permitir a destruição do que ainda resta das florestas nativas, o ritmo atual de desmatamento aponta na direção oposta.

Ao longo desses 500 anos, a área desmatada dos biomas Amazônia, Floresta Atlântica e Cerrado totalizou $270 \times 10^{6}$ ha, cerca de $32 \%$ do território brasileiro. Nos últimos 50 anos, a expansão da fronteira agrícola em direção aos cerrados causou a destruição de $60 \%$ de sua área original; na metade desse tempo, a Amazônia perdeu cerca de $15 \%$ de sua área. Os remanescentes da Floresta Atlântica somam, hoje, menos de $7 \%$ da extensão ocupada à época do descobrimento (HENRIQUES, 2003).

Objetivando disciplinar e limitar as interferências antrópicas sobre o meio ambiente, o artigo 2 do Código Florestal Brasileiro - a Lei no 4.771, de 15 de setembro de 1965 - contempla a criação das Áreas de Preservação Permanente (APP). Nessas áreas não se pode fazer a retirada da cobertura vegetal original, permitindo, assim, que ela possa exercer, em plenitude, suas funções ambientais (SOARES et al., 2002). Mais recentemente, tendo em vista os compromissos assumidos pelo Brasil perante a Declaração do Rio de Janeiro de 1992 e a necessidade de se regulamentar aquele artigo, entra em vigor, no dia 13 de maio de 2002, a Resolução no 303, do Conselho Nacional do Meio Ambiente CONAMA. Essa resolução estabelece parâmetros, definições e limites referentes às APPs e adota, ainda que implicitamente, a bacia hidrográfica como unidade de sua aplicação.

Os últimos 40 anos foram testemunhas da evolução de uma consciência ecológica no Brasil, marcada por grandes avanços em nossa legislação ambiental. Infelizmente, muitas dessas conquistas ainda não saíram do papel. Isso decorre basicamente de dois fatores: primeiro, a inexistência da demarcação oficial das áreas de preservação permanente, para vetar, em seu nascedouro, o licenciamento ambiental indevido; segundo, a constatação da deficiência estrutural do Estado, inviabilizando promover-se efetiva fiscalização ambiental em um país de dimensões continentais. Por essas e outras razões, até há bem pouco tempo esse capítulo do Código Florestal não despertava maiores preocupações naqueles que vêm usando a terra em desacordo com a legislação vigente.

A topografia é um controle dominante nos processos de superfície. Ela é um agente moderador na distribuição espacial do clima que, em última instância, dita a distribuição e a produtividade dos sistemas biológicos (HUTCHINSON, 1996). Isso, por si só, justifica a adoção da bacia hidrográfica como unidade natural de planejamento ambiental. Em adição, reduz-se consideravelmente a possibilidade de futuros conflitos sobre o uso da água, tornando-se efetivas as práticas de recuperação dos mananciais e revegetação das bacias de cabeceira, uma vez que o problema é tratado de forma holística.

Os métodos convencionais de obtenção manual das características fisiográficas das bacias hidrográficas a partir de mapas topográficos são tediosos e intensivos em mão-de-obra, representando sempre um grande desafio mesmo para técnicos experientes (GARBRECHT e MARTZ, 2000). Até o advento dos sistemas de informações geográficas, qualquer tentativa de obter parâmetros mais complexos como declividade, comprimento da hidrografia, trajeto de escoamento superficial, área de contribuição etc. para grandes extensões era dificultada, sobremaneira, pelo volume de trabalho, limitando, assim, aplicações potenciais de análise de drenagem. Além disso, a ausência de padrões tornava virtualmente impossível o armazenamento e o compartilhamento desse tipo de informações analógicas. Dentre as vantagens de se adotarem abordagens automatizadas para tais processos, destacam-se a confiabilidade e a reprodutibilidade dos resultados, que podem então ser organizados e facilmente acessados sob a forma de bases de dados digitais (SAUNDERS, 1999).

\section{R. Árvore, Viçosa-MG, v.29, n.2, p.203-212, 2005}


Atualmente, os principais sistemas de informações geográficas comercialmente disponíveis já contam com diversos recursos para uma modelagem numérica do relevo bastante acurada (TRIBE, 1992). A recente disponibilização gratuita pela NASA dos dados da Shuttle Radar Topography Mission (SRTM ${ }^{4}$ ) - uma rede de células quadradas de $90 \mathrm{~m}$ de lado contendo valores acurados de altimetria - para todo o continente americano, aliada à tecnologia de geração de modelos digitais de elevação hidrologicamente consistentes, viabilizam a delimitação automática das áreas de preservação permanente para todo o território brasileiro. Isso confere rapidez, confiabilidade e facilidade de identificação de conflitos de uso da terra usando imagens orbitais atualizadas, abrindo-se espaço para uma nova era: a do monitoramento ambiental inteligente.

Diante do exposto, este trabalho teve como objetivo demonstrar a viabilidade técnica de se fazer cumprir plenamente o Código Florestal brasileiro, no que se refere à delimitação de áreas de preservação permanente, em uma bacia hidrográfica com topografia acidentada.

\section{MATERIAL E MÉTODOS}

\section{1. Área de estudo}

A área de estudos selecionada foi a microbacia do córrego do Paraíso, com área de 212 ha, situada no município de Viçosa, Estado de Minas Gerais. Como referência, o centróide dessa área possui as seguintes coordenadas geográficas: $20^{\circ} 48^{\prime}$ de latitude sul e 42 $53^{\prime}$ ' de longitude oeste. A altitude na bacia varia entre 680 e $850 \mathrm{~m}$.

\subsection{Base de dados, equipamento e software utilizados}

A base de dados utilizada foi produzida por restituição manual de fotografias áreas na escala de 1:10.000 (SOARES et al., 2002). Posteriormente, os dados foram vetorizados, utilizando-se de uma mesa digitalizadora Summagraphics modelo Summagrid-III, com resolução de 1.000 dpi. Integraram essa base curvas de nível com eqüidistância vertical de $10 \mathrm{~m}$ e a rede hidrográfica, conforme representado na Figura 1.

\footnotetext{
${ }^{4}$ http://seamless.usgs.gov
}

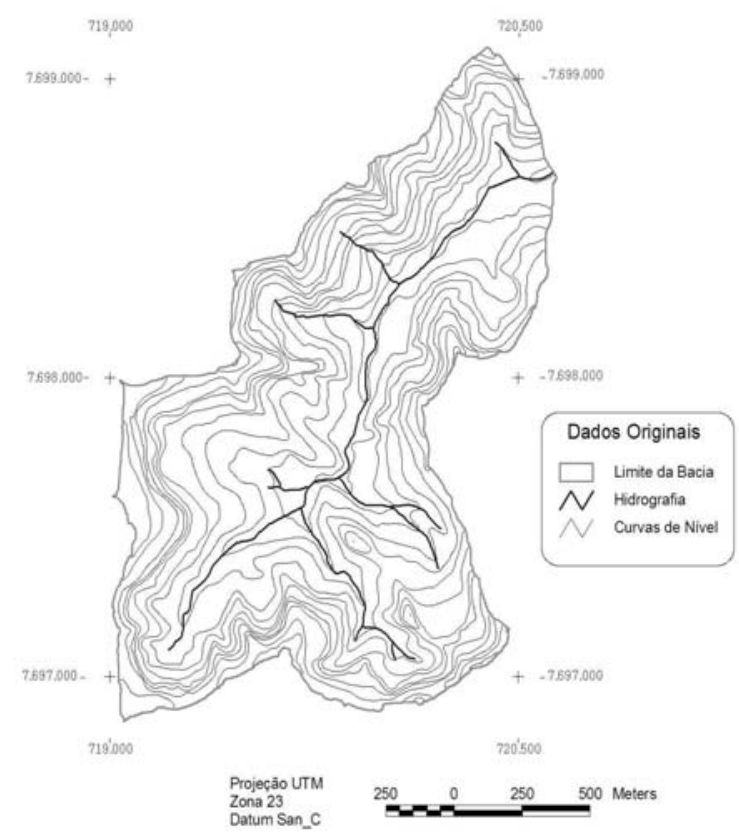

Fonte: Soares et al. (2002)

Figura 1 - Localização da área de estudo. Figure 1 -Location of the study area.

\subsection{Delimitação das APPs}

O ponto de partida para a delimitação automática das APPs é a geração de um modelo digital de elevação hidrologicamente consistente (MDEHC) para área de estudo. Esses modelos apresentam uma coincidência acentuada entre a drenagem derivada numericamente e a hidrografia real, estando isentos de sumidouros (depressões espúrias) que bloqueiem o trajeto do escoamento de água superficial (HUTCHINSON, 1989). Para tanto, há que se impor a hidrografia mapeada e, quando disponíveis, os divisores d'água como linhas de ruptura durante a interpolação dos dados de altimetria. Posteriormente, fazem-se refinamentos no modelo digital de elevação, ao longo da calha dos rios. Finalmente, deriva-se a direção de escoamento, assegurando-se que o escoamento superficial convirja para a calha do rio e, dentro da calha, para a foz da bacia (RUBERT et al., 1999; RIBEIRO et al., 2002). Utilizando-se essa base de dados, gerou-se o MDEHC com uma resolução de $2 \mathrm{~m}$, compatível com a exatidão cartográfica para a escala de 1:10.000.

R. Árvore, Viçosa-MG, v.29, n.2, p.203-212, 2005 
No processo manual de delimitação das APPs, o operador deverá estar, obrigatoriamente, considerando sempre duas referências: uma superior (o divisor de águas) e outra inferior (a base do morro ou o curso d'água), para somente então poder identificar com segurança onde situar-se-á a linha do terço superior da encosta. Além disso, há que se garantir que os três pontos considerados estejam ao longo do mesmo trajeto de escoamento superficial. Se essa condição não for atendida, o ponto intermediário certamente não estará sobre o terço superior da encosta!

Porquanto represente o maior desafio do processo manual, sendo a sua principal causa de erros, tal condição é exatamente o alicerce da metodologia consubstanciada no processo automatizado. São produzidos dois temas digitais no formato matricial (grid): um contendo, para cada uma de suas células, a altitude da célula da hidrografia (ou da base do morro) que lhe for mais próxima; outro contendo, para cada uma de suas células, a altitude da célula do divisor de águas (ou do topo do morro) que lhe for mais próxima. De posse do modelo digital de elevação da bacia analisada, a tarefa de identificar se uma célula pertence ou não ao terço superior é uma simples operação algébrica:

$[(\mathrm{MDEHC}-\mathrm{Base}) /($ Topo - Base $)] \geq(2 / 3)$.

Desenvolveram-se procedimentos para automatizar o delineamento dos seguintes tipos de áreas de preservação permanente: terço superior de morros e montanhas, terço superior de encostas e ao redor de nascentes. A implementação desses procedimentos foi feita utilizando-se o módulo Grid do Arc/INFO, versão 8.2 para Windows XP.

\subsubsection{Delimitação das APPs em topos de morro e montanhas}

O CONAMA adota, em sua Resolução no 303 , as seguintes definições:

- "morro - elevação de terreno com cota do topo em relação à base entre $50 \mathrm{~m}$ e $300 \mathrm{~m}$ e encostas com declividade superior a $30 \%$ na linha de maior declividade."

- "montanha - elevação de terreno com cota do topo em relação à base superior a 300 m."

- "base de morro ou montanha - plano horizontal definido por planície ou superfície de lençol d’água adjacente ou, nos relevos ondulados, pela cota da depressão mais baixa ao seu redor."

R. Árvore, Viçosa-MG, v.29, n.2, p.203-212, 2005
A identificação de morros e montanhas é feita invertendo-se o modelo digital de elevação, sendo os topos identificados como depressões. Para cada depressão, identifica-se a respectiva bacia de contribuição, cujo contorno representará, então, a base do morro ou montanha. Após isolar-se cada elevação do terreno que satisfazia os critérios mencionados, e com base nos valores de altimetria, delimitou-se o respectivo terço superior.

\subsubsection{Delimitação das APPs ao longo das linhas de cumeada}

A determinação das APPs nas linhas de cumeada (divisores de água) tem por base a bacia de contribuição de cada segmento da hidrografia. Entende-se por segmento o trecho da hidrografia compreendido entre uma nascente e uma confluência, entre duas confluências sucessivas ou, ainda, entre uma confluência e a foz da malha hidrográfica. Para se mapear o terço superior de uma encosta há que se saber, para cada célula do relevo, qual é a célula do divisor d'água que lhe é mais próxima e também qual é a célula da hidrografia que lhe é mais próxima. Somente após isso é que poderse-á identificar se dada célula pertence ou não ao terço superior de uma encosta, conforme ilustrado na Figura 2.

Esse procedimento fundamenta-se no trajeto do escoamento superficial ao longo das encostas. Considerando que a definição de linha de cumeada adotada pelo CONAMA reporta-se às definições de morro e de montanha, a determinação do terço superior somente será efetuada para os trechos das encostas que satisfizerem aquelas condicionantes.

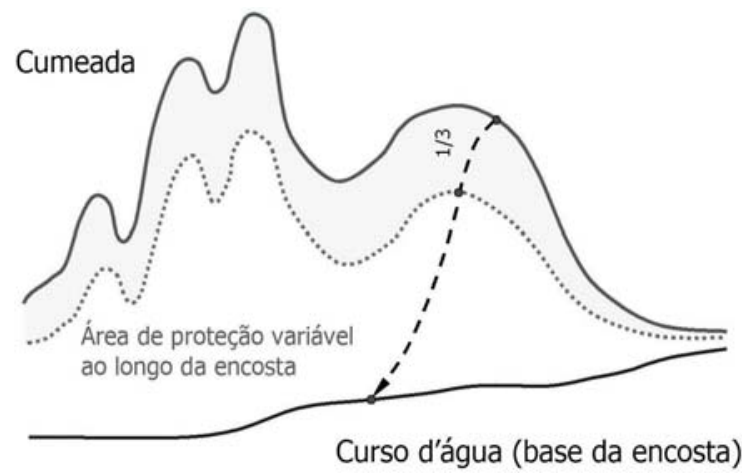

Figura 2 - Identificação do terço superior de uma encosta. Figure 2 -Delineation of the upper third of the hillside. 


\subsubsection{Delimitação das APPs ao redor de nascentes ou olhos d'água}

Identificaram-se todas as nascentes da rede hidrográfica, demarcando-se um raio de $50 \mathrm{~m}$ em torno de cada uma delas. Em seguida, e em consonância com as definições constantes da Resolução no 303 do CONAMA (Constitui Área de Preservação Permanente a área situada ... ao redor de nascente ou olho d'água, ainda que intermitente, com raio mínimo de cinqüenta metros de tal forma que proteja, em cada caso, a bacia hidrográfica contribuinte), delimitou-se a bacia de contribuição de cada nascente, procedendo-se, finalmente, à união dessas duas áreas, que constituem essa categoria de APPs.

\subsubsection{Outras categorias de APPs}

Além dessas três categorias, o Código Florestal contempla ainda outros tipos de áreas de preservação permanente. Vale destacar as matas ciliares e as regiões com declividades superiores a $100 \%$. Devido à facilidade de delineamento no campo ou a partir de mapeamentos detalhados, essas duas categorias constituem a grande maioria das áreas de preservação permanente ora fiscalizadas e, portanto, demarcadas. As zonas de proteção ao longo da hidrografia têm sua largura determinada pela largura do curso d'água medida por ocasião da cheia sazonal.

\section{RESULTADOS E DISCUSSÃO}

Na primeira fase desse trabalho, delimitaram-se as áreas de preservação permanente localizadas em topo de morros. Foram identificados 78 cumes no interior da bacia de estudo. Observa-se, na parte (a) da Figura 3 , que a maioria desses morros situa-se nas proximidades da rede hidrográfica. Na Figura 3 (b), apresentam-se os oito morros que atendem ao primeiro critério: que uma elevação tenha pelo menos $50 \mathrm{~m}$ de altura e menos de $300 \mathrm{~m}$ (morro) ou, então, mais de $300 \mathrm{~m}$ (montanha) e, assim, ser objeto de análise no processo de delimitação de áreas de preservação ambiental.

A Figura 3 (c) ilustra apenas os cinco morros que, além de terem altura entre $50 \mathrm{~m}$ e $300 \mathrm{~m}$, atendem também à segunda exigência que caracteriza um morro: possuir declividade acima de $30 \%$ na linha de maior declive. Não foi identificada, na área de estudos, nenhuma montanha.

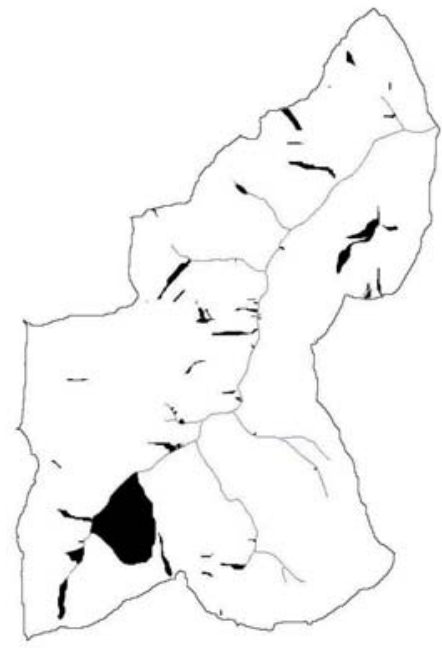

(a)

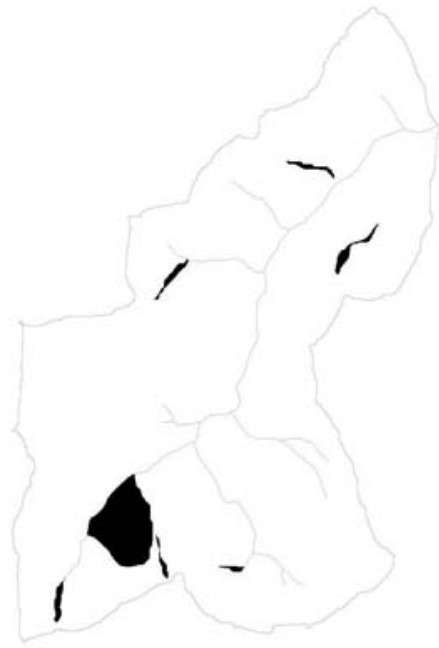

(b)

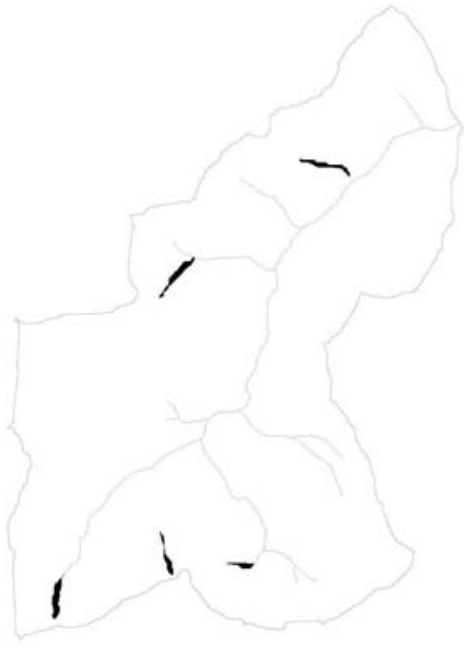

(c)

Figura 3 - (a) Localização dos morros dentro da bacia hidrográfica, (b) morros com pelo menos $50 \mathrm{~m}$ de altura e (c) morros com pelo menos $50 \mathrm{~m}$ de altura e declividade acima de $30 \%$ na linha de maior declive.

Figure 3 - (a) Location of the hills identified within the watershed, (b) hills at least 50m high and (c) hills at least $50 \mathrm{~m}$ high and with most slopes above $30 \%$. 
Na Figura 4, apresentam-se as APPs de topos de morros na bacia do córrego do Paraíso, que somam $2.840 \mathrm{~m}^{2}$, ocupando cerca de $0,13 \%$ da área total da bacia.

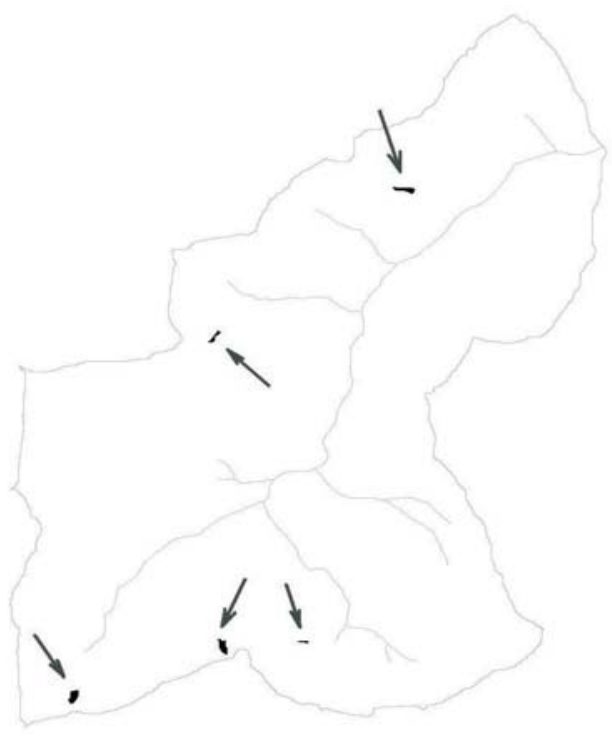

Figura 4 - Identificação das áreas de preservação permanente em topos de morros.

Figure 4 -Identification of natural preserves on hilltops.
Na Figura 5, apresentam-se as áreas localizadas no terço superior da encosta de cada sub-bacia, destancando as linhas de cumeada e a respectiva malha hidrográfica. Na parte (a) dessa figura, mostram-se o terço superior de cada sub-bacia, sem impor restrição de qualquer natureza. Na parte (b), atendendo aos dispositivos legais, eliminam-se os trechos da linha de cumeada que possuem altura inferior ou igual a $50 \mathrm{~m}$. Percebe-se, nessa figura, em ambos os casos, fragmentação nas áreas designadas como de proteção ambiental. Isso se deve às características do relevo naqueles trechos; especificamente, morros cujas bases se situam total ou, mesmo, parcialmente dentro do terço superior da encosta.

O terço superior das encostas da bacia do córrego do Paraíso, tal como se apresenta nas Figuras 5 (a) e 6, ocupa uma área de 75 ha, ou seja, aproximadamente $35 \%$ da área da bacia. Atendendo à legislação, a área efetivamente a ser protegida ao longo das linhas de cumeada, conforme mostrado nas Figuras 5 (b) e 7 , é de 55 ha, representando cerca de $26 \%$ da superfície dessa bacia.

As áreas em um raio de $50 \mathrm{~m}$ ao redor das nascentes da microbacia do córrego do Paraíso somam 8 ha. Considerando-se que as respectivas bacias de

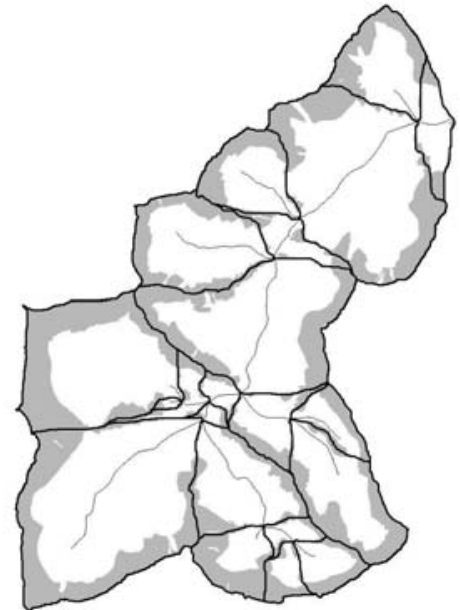

(a)

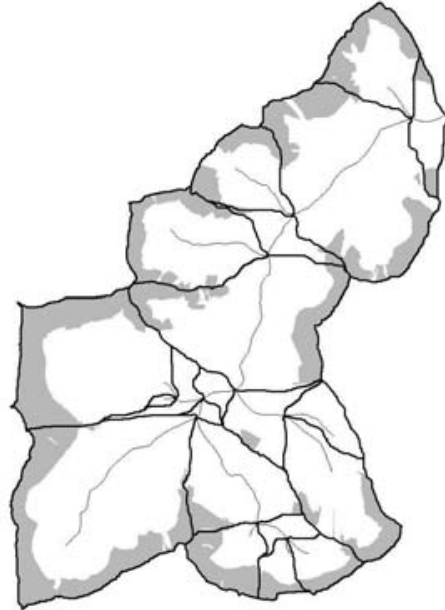

(b)

Figura 5 - Áreas de preservação permanente ao longo de linhas de cumeada: (a) considerando-se todo o terço superior de cada sub-bacia e (b) somente o terço superior dos trechos da linha de cumeada com altura igual ou superior a $50 \mathrm{~m}$.

Figure 5 - Natural preserves along ridgelines: (a) considering the upper third of the hillside and (b) limited to ridgelines' segments at least $50 \mathrm{~m}$ high.

R. Árvore, Viçosa-MG, v.29, n.2, p.203-212, 2005

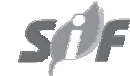


contribuição deverão também ser incorporadas à proteção das nascentes, essa categoria de APP totaliza 70 ha, cobrindo cerca de $33 \%$ da superfície dessa bacia, conforme mostrado na Figura 8. Observa-se, nessa figura, que, quanto mais distante dos seus divisores situar-se a nascente de um curso d'água, maior será a área protegida a montante.

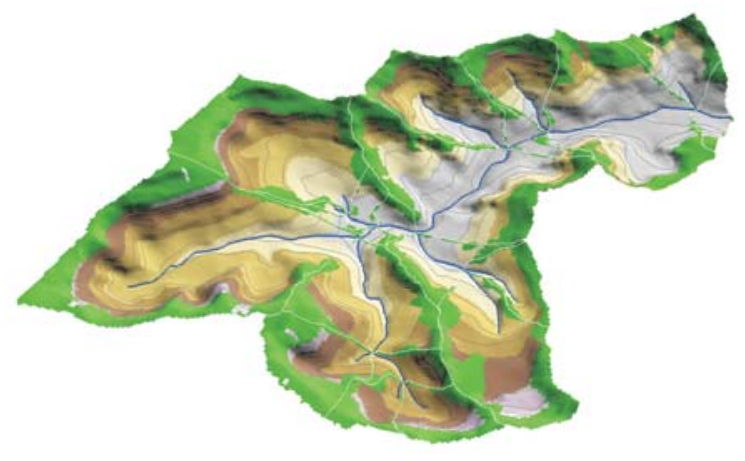

Figura 6 - Perspectiva do terço superior das encostas. Figure 6-Perspective view of the upper third of the hillside.

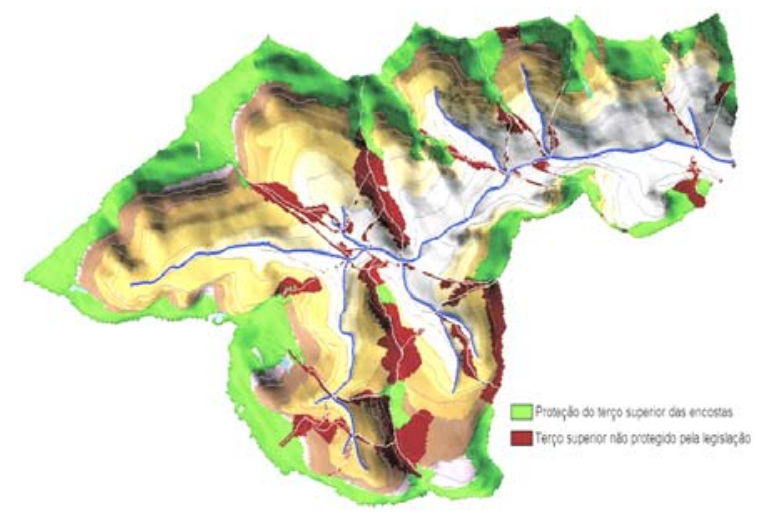

Figura 7 - Perspectiva das áreas de preservação permanente nas linhas de cumeada (verde), destacando-se as exclusões (marrom) efetuadas em função dos parâmetros da legislação.

Figure 7 -Perspective view of the natural preserves along ridgelines (green) highlighting the unprotected areas (brown) of the upper third of the hillsides due to legislation.

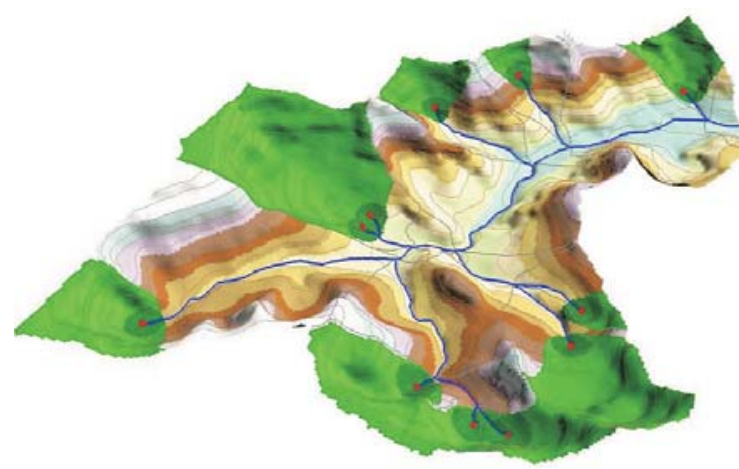

Figura 8 - Perspectiva das áreas de preservação permanente ao redor de nascentes (pontos vermelhos), destacandose as áreas associadas a um raio de $50 \mathrm{~m}$ (verde escuro).

Figure 8-Natural preserves on upland catchments, highlighting the $50 \mathrm{~m}$-radius circles (darker green) around the springs (red dots).

Na Figura 9 (a), mostram-se as áreas de preservação permanente ao longo da hidrografia estudada, apresentando uma largura uniforme de $30 \mathrm{~m}$ em cada margem. Isso se deve ao fato de as larguras desses córregos serem inferiores a $10 \mathrm{~m}$ no período chuvoso. Essa categoria ocupou 30 ha da área total da microbacia, representando cerca de $14 \%$. As áreas com diclividades acima de $100 \%$ são apresentadas na Figura 9 (b) e ocupam aproximadamente $2 \mathrm{ha}$, algo em torno de $1 \%$ da superfície total.

A Figura 10 ilustra a distribuição espacial de todas as áreas de preservação permanente na região estudada. Considerando-se as cinco categorias mencionadas, o Código Florestal promove a proteção efetiva de 123 ha, o que corresponde a cerca de $58 \%$ da área total dessa microbacia.

No Quadro 1, sintetiza-se a contribuição isolada de categoria de área de preservação permanente, não sendo contabilizadas as eventuais superposições.

Na Figura 11, estabelece-se uma comparação visual entre os resultados obtidos por restituição estereoscópica manual (SOARES et al., 2002) e os conseguidos de forma automática para as APPs situadas ao longo dos divisores d'água e no terço superior dos morros. Para essas duas categorias, a área delimitada visualmente totalizou 46 ha, equivalendo a cerca de $22 \%$ da área total da bacia. As setas apontam as diferenças entre os resultados (omissão e inclusão) obtidos pelos dois métodos.

R. Árvore, Viçosa-MG, v.29, n.2, p.203-212, 2005 


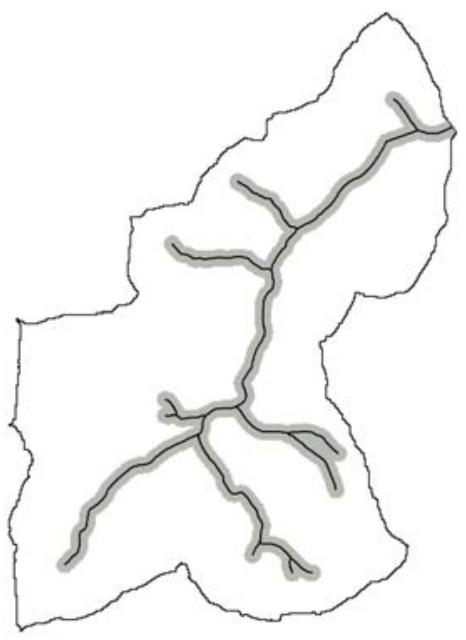

(a)

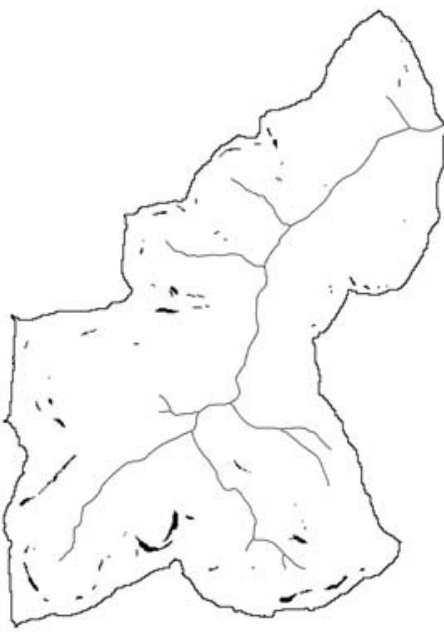

(b)

Figura 9 - Outras categorias de áreas de preservação permanente: (a) ao longo da hidrografia e (b) em terrenos com declividades superiores a $100 \%$.

Figure 9 -Other categories of permanent preservation areas: (a) riparian zones and $(b)$ slopes greater than $100 \%$.

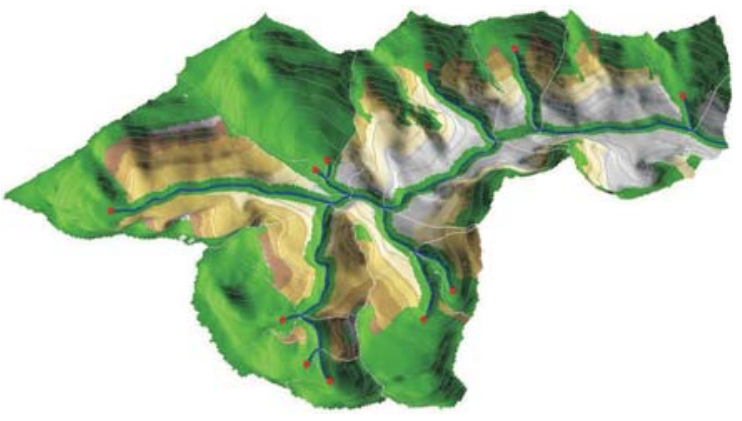

Figura 10 - Distribuição espacial das áreas de preservação permanente da microbacia do córrego Paraíso.

Figure 10 - Spatial distribution of the natural permanent preservation areas for the Paraíso creek basin.

Quadro 1 - Superfície total da microbacia do córrego do Paraíso protegida por categoria de área de preservação permanente

Table 1 - Protected surface in the Paraíso creek basin by category of permanent preservation area

\begin{tabular}{lcc}
\hline Categoria & Área (ha) & $\begin{array}{c}\text { Percentual da } \\
\text { microbacia }\end{array}$ \\
\hline Ao redor de nascentes & 70 & $33 \%$ \\
Terço superior de encostas & 55 & $26 \%$ \\
Matas ciliares & 30 & $14 \%$ \\
Áreas declivosas & 2 & $1 \%$ \\
Topo de morros & 0,28 & $0,13 \%$ \\
\hline
\end{tabular}

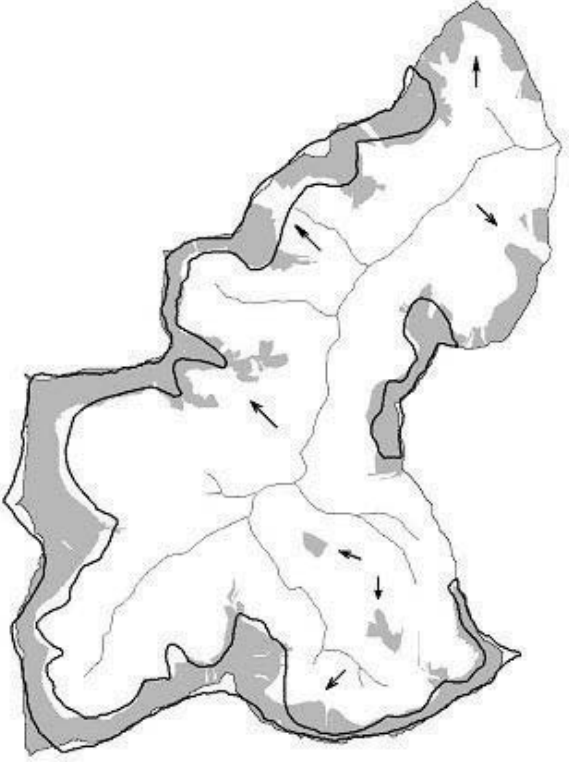

Figura 11 - Superposição dos resultados da delimitação visual (linha preta) das áreas de preservação permanente com os da delimitação automática (cinza).

Figure 11 - Superimposition of natural preserves visually delineated using aerial photos (solid black line) and the results of automated delineation via GIS (gray).

R. Árvore, Viçosa-MG, v.29, n.2, p.203-212, 2005 


\section{CONCLUSÕES}

Com relação à bacia hidrográfica analisada, podese concluir que:

a) As áreas de preservação permanente ocuparam mais da metade da área total da bacia.

b) A preservação das nascentes responde, isoladamente, pela maior extensão (33\%) das áreas protegidas, seguida pela categoria de preservação do terço superior das encostas $(26 \%)$.

c) A delimitação das APPs em topos de morros e ao longo das linhas de cumeada requer, necessariamente, que a demarcação seja feita com base nos limites da bacia hidrográfica.

d) O relevo da microbacia do córrego do Paraíso é bastante representativo da topografia dessa região, e, assim, as conclusões desse estudo podem ser seguramente extrapoladas para regiões com características topográficas semelhantes.

e) Ocorre a coalescência natural entre as APPs das nascentes com as APPs situadas ao longo dos divisores d'água e destas com as zonas de proteção riparianas, formando, assim, um grande corredor ecológico ao longo de todas as bacias hidrográficas.

f) A partir do mapeamento das APPs, a definição geográfica das reservas legais poderá apoiar-se em critérios ecologicamente estabelecidos, contribuindo para complementar eventuais lacunas e promover a melhoria na forma e função das áreas de preservação permanente.

g) A comparação visual entre os resultados deste trabalho com aqueles obtidos por restituição analógica de fotografias aéreas aponta para uma coincidência consideravelmente alta entre os dois métodos.

h) A delimitação automática das APPs elimina a subjetividade do processo, viabilizando o fiel cumprimento do Código Florestal brasileiro, favorecendo a fiscalização ambiental.

i) A partir de agora, não mais se podem invocar as dificuldades conjunturais e as deficiências estruturais para continuar promovendo impunemente a degradação ambiental.

\section{REFERÊNCIAS BIBLIOGRÁFICAS}

FAO. Forest Resources Assessment 2000: Main Report. Rome. 2001. (FAO Forestry Paper, 140).

GARBRECht, J.; MARTZ, L. W. Paper 1 Digital elevation model issues in water resources modeling. In: MAIDMENT, D.; DJOKIC, D. (Eds). Hydrologic and hydraulic modeling support with geographic information systems. Redlands: Environmental Systems Research Institute, 2000. p.1-28.

HENRIQUES, R.P.B. O futuro ameaçado do cerrado brasileiro. Ciência Hoje, v.33, n.195, p.34-39, 2003

HOUGHTON, R.A. The worldwide extent of land-use change. Bioscience, v.44, p.305-315, 1994.

HUTCHINSON, M.F. A new procedure for gridding elevation and stream line data with automatic removal of spurious pits. Journal of Hydrology, v. 106, n.3-4, p.211-232, 1989.

HUTCHINSON, M.F. A locally adaptive approach to the interpolation of digital elevation models. In: INTERNATIONAL CONFERENCE/WORKSHOP ON INTEGRATING GIS AND ENVIRONMENTAL MODELING.

Proceedings... Santa Bárbara: National Center for Geographic Information and Analysis. University of California, 1996. CD-ROM.

RAVIKANTH, G.; SHAANKER, R.U.; GANESHAIAH, K.N. Conservation status of forests in India: a cause for worry?. Journal of the Indian Institute of Science, v. 80, n.6, p.591-600, 2000.

RIBEIRO, C.A.A.S. et al. Modelos digitais de elevação hidrologicamente consistentes para a Amazônia Legal. In: SIMPÓSIO DE RECURSOS HÍDRICOS DO CENTRO-OESTE, 2., 2002, Campo Grande. Anais... Campo Grande: 2002. CDROM.

R. Árvore, Viçosa-MG, v.29, n.2, p.203-212, 2005 
RUBERT, O. A.; RIBEIRO, C. A. A. S.; CHAVES, M. A. Um novo divisor de águas na geração de modelos digitais de elevação hidrologicamente consistentes. In: SIMPÓSIO BRASILEIRO DE RECURSOS HÍDRICOS, 13., 1999, Belo Horizonte. Anais... Belo Horizonte: 1999. CD-ROM.

SAUNDERS, W. Preparation of DEMs for use in environmental modeling analysis. In: ESRI

INTERNATIONALUSER CONFERENCE.

Proceedings... San Diego: 1999. CD-ROM.
SOARES, V.P. et al. Avaliação das áreas de uso indevido da terra em uma microbacia no município de Viçosa - MG, através de fotografias aéreas e sistemas de informação geográfica. Revista Árvore, v.26, n.2, p.243-251, 2002.

TRIBE, A. Automated recognition of valley lines and drainage networks from grid digital elevation models: a review and a new method. Journal of Hydrology, v.139, p.263-293, 1992. 